\title{
Estratégias multidimensionais para a avaliação da aprendizagem em cursos on-line
}

Gerson Pastre de Oliveira*

\section{Resumo}

Este trabalho traz os resultados de uma investigação de caráter qualitativo, apoiada em descrições provenientes de um curso de especialização on-line colaborativo, com ênfase no processo de avaliação da aprendizagem dos estudantes. A investigação mostrou que, em decorrência das possibilidades abertas às pessoas pelas tecnologias de informação e comunicação, o processo avaliativo não pode se limitar à lógica do exame, pós-processual e definitivo, mas deve estender-se a todos os momentos, formas, atividades e práticas de um ambiente de curso. Esta abordagem, de caráter multidimensional, é capaz de dar conta do caráter complexo do conhecimento pertinente, levando em consideração as múltiplas possibilidades de interação, os diferentes tempos e espaços de aprender e ensinar, e as interfaces correspondentes, bem como as abordagens interdisciplinares presentes no ambiente colaborativo analisado. As referências teóricas exploraram os conceitos de avaliação e sua prática predominante, além de tratar dos diversos aspectos das tecnologias de informação e comunicação aplicadas à educação. Com base nestas duas frentes principais, outros conceitos foram contemplados no campo teórico, como complexidade, colaboração, tempo, espaço, interdisciplinaridade, entre outros, o que permitiu à pesquisa basear-se em um arcabouço de idéias a partir das quais as análises foram trazidas à luz, de forma a mostrar as amplas possibilidades da avaliação multidimensional da aprendizagem em ambientes colaborativos on-line, a qual oportuniza o ajuste dos objetivos individuais de estudantes e professores em função de uma estratégia pedagógica que privilegia dialeticamente a construção coletiva do conhecimento e a autonomia. Outro ponto importante demonstrado nesta investigação é a importância das pessoas, acima das tecnologias, e da colaboração entre as pessoas para uma avaliação de todos os momentos, inclusive considerando as trajetórias de cada participante, como sujeito detentor de história pessoal e de conhecimentos advindos de múltiplas fontes, em permanente estado de elaboração.

Palavras-chave: Avaliação. Educação a distância. Ensino-aprendizagem. Colaboração. Cursos on-line. Avaliação multidimensional.

* Doutor em Educação, Universidade de São Paulo (USP); Professor, Pontifícia Universidade Católica de São Paulo (PUC/SP). 


\section{Multidimensional strategies for learning evaluation in on-line courses Abstract}

This work presents the results of a qualitative investigation supported by descriptions from an on-line collaborative specialization course with emphasis on the evaluation process of students' learning. The investigation showed that, as a result of the possibilities both information technology and communication technology create to people, the evaluation process can not be limited to the logic of a post-procedural and definitive examination, it should rather be applied all time long, in all ways and for all activities and practices in a course environment. This approach has a multidimensional nature and is able to handle with the complexity of the related knowledge, taking into account many possibilities of interaction, different timing and spaces to learn and teach, the related interfaces as well as interdisciplinary approaches in the analyzed collaborative environment. The theoretical references have explored the evaluation concepts and its predominant practice, and examine several aspects of information and communication technology which apply to the education. Based on these two main fronts, other concepts have been considered in the theoretical field such as complexity, collaboration, time, space, interdisciplinary aspects, among others, which have allowed the research to have its basis on a framework of ideas from which the analysis have been brought to light in order to show the broad scope of the multidimensional learning evaluation in on-line collaborative environment, considering that such evaluation allows to set individual goals of students and teachers according to a pedagogical strategy that dialectically focuses the autonomy and the collective construction of knowledge. Another important point demonstrated in this investigation is that people are much more important than technologies, and that the collaboration between people is also important for an assessment of all moments, even considering the history of each participant as an individual who has a personal history and knowledge gathered from multiple sources and being continuously processed.

Keywords: Evaluation. Distance education. Teaching and learning. Collaboration. On-line courses. Multidimensional evaluation.

\section{Estrategias multidimensionales para la evaluación de aprendizaje en cursos en linea Resumen}

Esto trabajo presenta los resultados de una investigación de carácter cualitativo basada en descripciones provenientes de un curso de especialización en línea colaborativo con énfasis en el proceso de 
evaluación del aprendizaje de los estudiantes. La investigación mostró que, como resultado de las posibilidades abiertas a las personas por las tecnologías de información e comunicación, el proceso de evaluación no puede limitarse a la lógica del examen sino que debe extenderse a todos los tiempos, las formas, las actividades y prácticas en un entorno de curso. Esto enfoque, de carácter multidimensional, es capaz de dar cuenta del carácter complejo de los conocimientos pertinentes, teniendo en cuenta las múltiples formas de interacción, diferentes momentos y espacios y las correspondientes interfaces, y los enfoques interdisciplinarios en el entorno colaborativo examinado. Los referentes teóricos exploraron los conceptos de evaluación e su práctica predominante, además de abordar diversos aspectos de tecnologías de información y comunicación aplicadas a la educación. Basándose en estos dos frentes principales, otros conceptos se incluyen en las bases teóricas, como la complejidad, la cooperación, el tiempo, espacio, la interdisciplinariedad, entre otros, lo que permitió a la investigación apoyarse en un conjunto de ideas por las cuales el análisis fue hecha, para presentar la amplia posibilidad de la evaluación multidimensional del aprendizaje en entornos colaborativos en línea que fomentan el ajuste de las metas individuales de los estudiantes y profesores en una estrategia pedagógica que enfatiza dialécticamente la construcción colectiva de conocimientos y la autonomía. Otro punto importante ha demostrado en esta investigación es la importancia de las personas por encima de las tecnologías, y de la colaboración entre las personas a una evaluación de todos los momentos, incluso teniendo en cuenta las trayectorias de cada participante, como sujeto que tiene una historia personal y conocimientos derivados de múltiples fuentes, en permanente estado de desarrollo. Palabras clave: Evaluación. Educación a distancia. Enseñanza y aprendizaje. Colaboración. Cursos en línea. Evaluación multidimensional.

\section{Introdução}

Falar de avaliação não é discutir sobre um tema simples. É importante deixar esta asserção bastante clara, porque boa parte do que se pratica sob o rótulo de avaliação é mera conferência, checagem, verificação. Claro que isto não é novidade, e muito se tem escrito no sentido de provocar debates em torno de avaliações que consigam abarcar os diversos momentos de processos educacionais, de forma a colaborar para aumentar o significado dos mesmos. E avaliações significativas são processuais, contínuas, proporcionam diálogos/debates, são orientadoras. Posicionam as pessoas quanto àquilo que aprendem e ensinam, sobre a pertinência de suas trajetórias, o acerto de seus projetos, a qualidade de seus planejamentos. Por isso, podem até ser expressas por conceitos ou notas, mas não devem, em princípio, permanecer adstritas a estas dimensões. 
0 domínio da avaliação da aprendizagem é, portanto, complexo e multidimensional. E a investigação descrita neste artigo aponta para cenários ainda mais exigentes no caso de cursos que se dão através de Ambientes Virtuais de Aprendizagem (AVA). Desta forma, antes de descrever os detalhes relativos à experiência em si, faz-se relevante trazer os pressupostos teóricos norteadores da pesquisa, em duas frentes essenciais: o trinômio complexidade-multidimensionalidade-interdisciplinaridade e as idéias relativas à avaliação em AVA.

\section{Avaliação}

Ao ampliar os espaços e tempos educacionais com auxilio da lógica provida pelos cursos on-line, não se promove, só por isso, uma revolução educacional. Entram em jogo as estratégias pedagógicas, que devem prever outras dinâmicas, outras abordagens, outras metodologias. A colaboração como conceito e sua implementação nas bases descritas neste trabalho em um curso on-line não pode ser instalada como uma opção de software - não vem em CD/DVD, não se "baixa" na Internet, não se compra como pacote. Permanece entre as dimensões das intervenções humanas, pessoais, de professores e alunos. E a avaliação da aprendizagem, incursa no processo, permeando-o por inteiro, não escapa desta característica. A abordagem colaborativa, uma vez implementada, pede avaliações que a acompanhem e ratifiquem como método de aprender em conjunto. É um desafio para professores e estudantes. E para vencê-lo, é preciso superar a predominância do modelo transmissor na educação, que se conecta a um modelo classificatório de avaliação da aprendizagem, considerando, como uma das possibilidades no contexto virtual, as atividades colaborativas como integradoras dos momentos de aprendizagem, ensino e avaliação, que passam a ocorrer ao mesmo tempo, atendendo "às novas demandas sociotécnicas de autonomia, multiplicidade de conexões, dialógica, colaboração e interatividade" (SILVA, 2006, p. 28).

Neste cenário, os sujeitos não permanecem como meros espectadores, mas como participantes ativos, que precisam assumir responsabilidades em relação à construção dos conhecimentos que buscam - e, não raro, em relação aos pares, o que envolve possibilidades de "mobilização de competências", e de "autoria e co-autoria" (SANTOS, 2006, p. 316). Além disso, os papéis são múltiplos, e envolvem tarefas que são da competência de todos, como aprender, ensinar, mediar, orientar, interagir, em maior ou menor escala para cada um deles, em diversos momentos.

A avaliação em cursos a distância, de forma geral, segue um modelo apoiado em três alternativas básicas (OTSUKA et al., 2002, p. 2):

Presencial: a avaliação é feita por meio de uma prova, na presença do formador ou de outra pessoa responsável, para garantir a legitimidade da mesma; 
Virtual com aplicação de testes on-line: a avaliação é feita por meio de mecanismos de testes on-line a serem respondidos e enviados posteriormente para o formador por meio de e-mail ou de formulários de envio;

Avaliação ao longo do curso (contínua): a avaliação é feita de modo contínuo, baseada em componentes que forneçam subsídios para o formador avaliar seus aprendizes de modo processual, tais como as atividades realizadas, os comentários postados, as participações em grupos de discussão e em chats, as mensagens postadas no correio, etc.

Segundo os autores supramencionados, as avaliações efetuadas em modo presencial são meramente classificatórias, pós-processuais, destinadas quase tão-somente ao atendimento dos critérios institucionais de promoção/retenção, não sendo em nada diferente dos modelos tradicionais que se baseiam em provas, exames e testes. Ressaltam os autores que, de acordo com o artigo $7^{\circ}$ do Decreto n'. 2.494 (BRASIL, 1998), a legislação nacional vigente impõe a forma presencial de avaliação da aprendizagem para julgar os processos de promoção, certificação ou diplomação.

Os autores supramencionados também comentam que, quando o processo avaliativo se dá a distância, através do suporte oferecido para um curso determinado (Word Wide Web, e-mail, programas tutores, mídias de armazenamento de massa, como CD-ROM, entre outros), na maior parte das vezes a avaliação está, também, baseada exclusivamente em testes somativos aplicados em momentos isolados do curso. São testes automatizados, que geram um feedback rápido (e também automatizado), com certos refinamentos em algumas iniciativas, buscando alguma individualização sob demanda do professor, que utiliza metadados relacionadores de tópicos e questões, na busca pela geração de um questionário relativamente personalizado. Questões adaptativas, por sua vez, também são usadas, sendo que a adaptação é, na maior parte das vezes, uma ligação entre o progresso indicado no ambiente do curso e o banco de dados de questões. Apesar dos refinamentos, trata-se de técnicas ligadas muito mais à reprodução de conteúdos e memorização, cujo alcance avaliativo é limitado, fragmentado, isolado e descontínuo.

Esta avaliação, sofisticada transposição dos exames e dos testes classificatórios tradicionais, representa a culminância de outra transposição, representada pela sala de aula virtual como reprodução digitalizada dos espaços presenciais tradicionais. A interatividade em seu aspecto meramente reativo, como já mencionado neste trabalho, cria uma lógica linear, na forma de seqüência de objetos textuais permeados por possibilidades limitadas de ação e reflexão (avançar e recuar nas páginas do mesmo, mas não intervir e debater, por exemplo). Após os textos, pontualmente, testes com feedbacks determinísticos aguardam o aluno, como corolários da reprodução que se perpetua, de acordo com Primo (2006). 
A avaliação em cursos que são oferecidos através de ambientes virtuais de aprendizagem colaborativa não é a mesma avaliação dos modelos tradicionais de ensino, baseados na reprodução e na memorização, ou de outras modalidades de instrução por transmissão verticalizada e hierárquica, no fluxo unidirecional professor-aluno. De fato, em cursos colaborativos on-line, outra avaliação da aprendizagem deve ter lugar. Algumas boas práticas podem ser apropriadas desde outras experiências de ensino-aprendizagem, nos múltiplos e diversificados ambientes nos quais esta experiência pode ocorrer. Mas esta apropriação não se fará sem a devida crítica ou sem o consistente planejamento, de modo a considerar as especificidades do ambiente virtual e os estilos de aprendizagem evidenciados pelos participantes. Sobre essas considerações:

Precisamos antes refletir sobre algumas peculiaridades desta modalidade de ensino $[\mathrm{EaD}]$, que torna a avaliação ainda mais complexa do que na modalidade presencial. A primeira peculiaridade vem do fato de existir pouco contato entre o professor/tutor e os alunos. Há outras, que são consequências desta primeira. Talvez a maior seja a de que a avaliação em EAD exige críticas ao paradigma tradicional e a necessidade de substituí-lo por outro (GAMA; OLIVEIRA, 2006, p.139).

A natureza atual que as pessoas têm dado aos ambientes virtuais aponta na direção desta mudança. Thorpe (apud OTSUKA et al., 2002, p. 3) assevera que os ambientes de aprendizagem digitais já não devem ser encarados como meros repositórios de dados e conceitos, mas estabelecem-se como locais de "interações, colaborações e de construção colaborativa do conhecimento".

Inicialmente, Paloff e Pratt (2002) mencionam que os cursos constituídos através de comunidades virtuais colaborativas podem ter dois tipos de avaliação da aprendizagem: uma de caráter somativo, ocorrendo ao final do curso, que é, segundo os autores, o modelo utilizado pela maioria das instituições acadêmicas; o outro modelo é o formativo, caracterizado pela dinâmica contínua, de modo a ter a possibilidade de ocorrer em qualquer momento do processo.

Argumentam Paloff e Pratt (2002) que a avaliação final somativa é apenas a mensuração do nivel de satisfação do aluno em relação ao curso e aos docentes, não representando, porém, "uma medida da dinâmica e do ritmo de aprendizagem do aluno". Na concepção dos autores, então,

Fazer apenas a avaliação final em um curso on-line é ignorar muitas das idéias importantes [...] relacionadas a esta forma de aprender e ensinar. Se os professores estiverem realmente implementando um processo colaborativo e transformador, devem usar tanto a avaliação final quanto a formativa. Esta ajuda a determinar até que ponto os mestres estão conseguindo facilitar ao 
aluno a reflexão sobre a matéria que estuda, sobre o meio de aprendizagem e sobre si próprio como estudante. A avaliação final, por sua vez, ajuda-nos a saber se atingimos os objetivos e os resultados projetados (PALOFF; PRAT, 2002, p.176).

Esta também é a posição de Harasim e outros (2005), nas quais as abordagens pedagógicas que tenham o aluno por centro deveriam incluir a avaliação como parte do processo de ensino-aprendizagem, de modo que a mesma esteja presente nas atividades de aula e nas múltiplas interações entre os participantes, alunos e professores. Desta forma, a avaliação apareceria como um processo contínuo construído na estrutura das aulas.

Para Santos (2006), na educação on-line, são objetos de uma avaliação processual tanto as atividades individuais quanto aquelas de caráter colaborativo e/ou cooperativo. É um trabalho que se encaixa na construção/transformação, que ocorre a partir da potencialização dos saberes prévios, que se tornam, diante das novas possibilidades, conhecimento potencial. Este movimento, inicial, diagnóstico, pode fornecer elementos para a criação de atividades eminentemente avaliativas que criem zonas de desenvolvimento proximais entre o saber potencial e o conhecimento real, de acordo com Vigotsky (1988) e Santos (2006). As atividades contínuas de avaliação multidimensional em cursos on-line colaborativos ocorrem justamente na atuação intencional dos docentes, na composição de uma estratégia pedagógica assumida por professores e tutores, que culmina em uma atuação avaliativa ampla, com engajamento de todos.

0 sucesso da avaliação da aprendizagem é vinculado, por autores como Paloff e Pratt (2002), ao seu caráter formativo, partindo da determinação, por parte dos professores, das diretrizes e dos resultados esperados da aprendizagem, bem como os próprios critérios de avaliação. Os autores acreditam que a amplitude dos materiais produzidos pelos estudantes deve ser considerado no processo de avaliação da aprendizagem, destacando as possibilidades avaliativas abertas pelo diálogo através das ferramentas usadas nos cursos on-line colaborativos.

Da mesma forma, Paloff e Pratt (2002) advogam um processo avaliativo amplo da aprendizagem, também de natureza colaborativa e processual, incluindo a autoavaliação e a avaliação dos colegas (outros estudantes). A importância da autoavaliação seria, entre outras, a de indicar, na percepção do próprio aluno, como foi seu progresso, o que pode diferir substancialmente da visão do professor. Os autores indicam que

receber e usar os comentários que [...] são enviados deve ser algo contínuo e rotineiro para a avaliação. A razão para se equiparar esse retorno ao desempenho é que esta é a única maneira de os alunos aprenderem a se autoavaliarem e, assim, autoajustarem seu desempenho intelectual, assim como fazem músicos, artistas e atletas (PALOFF; PRAT, 2002, p. 179). 
Estes comentários consagrariam a função de feedback para professores e alunos, advinda da avaliação da aprendizagem, quando a mesma tem um caráter processual. Isto fica claro em outro trabalho dos autores, quando mencionam que "o propósito da avaliação dispensada ao aluno é dar a ele 0 apoio e o feedback necessários à ampliação de sua aprendizagem e relatar o que já realizou" (PALOFF; PRAT, 2004, p. 111).

Para Primo (2006), os textos escritos pelos estudantes e suas reflexões sobre os objetos de pesquisa são elementos que permitem uma avaliação da aprendizagem muito mais rica e consistente do que aquela provida pelos testes somativos. Além disso, resenhas críticas, por eles propostas, são elementos que permitem problematizar as informações com as quais se deparam ao longo dos estudos. Estes trabalhos e atividades, entretanto, não são de exclusiva aferição por parte do docente, mas devem ser intensamente expostos à crítica coletiva, o que pode ser conseguido através da publicação dos mesmos na web, com a abertura para comentários. Desta maneira, cria-se a possibilidade de intervenção avaliativa dos pares, suscitando debates que podem oportunizar uma reflexão amadurecida em torno de questões como a qualidade da produção, a possibilidade de agregar novas idéias à mesma, de mudança de posicionamentos, etc. Neste ambiente de cooperação e de colaboração, o professor, mediador e orientador, pode intervir de forma problematizadora e crítica, em conjunto com os estudantes. Algumas interfaces que permitem semelhantes debates são o chat (síncrono) e o fórum (assíncrono), além de outras, como o portfólio,o diário de bordo,os blogs, entre outros.

\section{Multidimensionalidade-complexidade- interdisciplinaridade}

Para entender a multidimensionalidade da proposta avaliativa em análise neste estudo, inevitável abordar a questão da interdisciplinaridade. Partimos do princípio que este caráter multidimensional, que deve ser entendido como de acompanhamento em múltiplos sentidos e direções, que se faz ao longo do processo e de maneira constante, que se refere aos aspectos de correlação interna e externa dos saberes, bem como a suas interfaces, e que fornece elementos amplos sobre o processo de ensino-aprendizagem em cenários complexos, somente é possível a partir da quebra do particionamento, da compartimentalização rígida em disciplinas estanques, que não se comunicam e/ou que têm objetivos e trajetórias descoladas das demais.

Entretanto, muito mais do que uma simples relação entre as disciplinas, este conceito abrange as atividades propostas ao longo da experiência educativa como um todo, e também as relações sociais presentes na comunidade aprendente, suas interfaces com 0 mundo e com os outros saberes, prévios e construídos em paralelo. Toda esta trama vai sendo tecida continuamente, com múltiplas interconexões, ao longo do processo. Abrange também o próprio caráter colaborativo das interações, que não encontram limites rígidos nos períodos estabelecidos para início ou término de cada uma das disciplinas. 
Como unidades organizacionais e curriculares, estão presentes as disciplinas, como "categoria(s) organizadora(s) dentro do conhecimento"1 e as disciplinas permanecem, "intelectualmente, plenamente justificáveis", mas as mesmas não devem apresentar um caráter limitante: cada uma delas acrescenta seu foco ao processo de construção do conhecimento, além de criar aportes, relações e interconexões de múltiplos sentidos e direções com a construção já realizada até um ponto específico. Ou seja: devem preservar "um campo de visão que reconheça e conceba a existência das ligações e das solidariedades. E mais: só serão plenamente justificáveis se não ocultarem realidades globais"2.

Mas compete posicionar teoricamente estas asserções, primeiro quanto à multidimensionalidade. Em Morin (2002), o conceito do multidimensional é explicitado em relação ao ser humano e à sociedade. Para o autor, o ser humano tem um caráter múltiplo, "ao mesmo tempo biológico, psíquico, social, afetivo e racional", assim como a sociedade, com suas dimensões "histórica, econômica, sociológica, religiosa". Ao transpor a multidimensionalidade para a questão do conhecimento, 0 conhecimento pertinente precisa reconhecer este caráter multidimensional. Alem disso, para o autor, é necessário reconhecer a questão da complexidade. 0 próprio termo tem um sentido de tessitura conjunta:

\begin{abstract}
[...] há complexidade quando elementos diferentes são inseparáveis constitutivos do todo [...], e há um tecido interdependente, interativo e inter-retroativo entre o objeto de conhecimento e seu contexto, as partes e o todo, o todo e as partes, as partes entre si. Por isso, a complexidade é a união entre a unidade e a multiplicidade. Os desenvolvimentos próprios a nossa era planetária nos confrontam cada vez mais com os desafios da complexidade (MORIN, 2002, p. 38-39).
\end{abstract}

A contextualização da informação, aliás, é uma característica determinante do pensamento pertinente: "podemos dizer até que o conhecimento progride não tanto por sofisticação, formalização e abstração, mas, principalmente, pela capacidade de contextualizar e englobar" (MORIN, 2001a, p. 15). Também por isso, Bruno e Moraes (2006) comentam que, como fator que constitui a vida e a realidade, a complexidade indica a existência de uma "tessitura comum", que leva à inseparabilidade dos interagentes dos fenômenos, como sujeito e objeto, indivíduo e contexto. Segundo as autoras, desta maneira, fatos, fenômenos e objetos permanecem inter-relacionados, multidimensionais e interativos, o que se estende à aprendizagem, ela também, como o conhecimento, dotada das instabilidades, desordens e incertezas instauradas pelos cenários complexos da contemporaneidade. 
Ao contrário de um cenário anterior, no campo da aprendizagem, calcado em certezas mais ou menos sólidas e definitivas, a proposição da complexidade vem indicar uma ruptura com as estruturas pseudo-solidificadas do saber-certeza. 0 sujeito que sabe, invariavelmente, e que edificou seu conhecimento de forma inatacável e definitiva, abre espaço para o indivíduo que pergunta e que problematiza, isto mesmo a partir das incertezas, indeterminações, imprecisões, dúvidas e desordens típicas da complexidade.

Ao consolidar a compreensão de que a simplificação não é mais possivel nos cenários contemporâneos, Morin (2001b, p.177) indica que isso não corresponde à obtenção de quaisquer respostas ou receitas: "[...] a complexidade surge com dificuldade, como incerteza e não como clareza e como resposta. 0 problema é saber se há uma possibilidade de responder ao desafio da incerteza e da dificuldade". Desta forma, "perceber a transformação epistemológica em curso é perceber que lá, onde esperávamos encontrar o simples, está o complexo, o infinitamente complexo. Que quanto mais fina é a análise, maior a complexidade que se abre à nossa frente. E, portanto, que o todo não é a soma das partes" (POMBO 2004, p.11).

A complexidade e a multidimensionalidade encaminham o pensamento e a organização dos saberes, principalmente em contextos educacionais, para a interdisciplinaridade. Morin (2001a) indica que a divisão em disciplinas torna impossível captar 'o que é tecido junto', isto é, o complexo. Assim, a inteligência que apenas separa, fragmenta o complexo em partes separadas, divide os problemas, unidimensionaliza o multidimensional. Para Pombo (2004, p. 11), a interdisciplinaridade é um movimento inevitável:

A interdisciplinaridade não é qualquer coisa que nós tenhamos que fazer. É qualquer coisa que se está a fazer quer nós queiramos ou não. Nós estamos colocados numa situação de transição e os nossos projetos particulares não são mais do que formas, mais ou menos conscientes, de inscrição nesse movimento.

Se esta é a natureza do conhecimento, complexa, em contextos globais, multidimensional, como tratar, na educação, e, principalmente, na avaliação da aprendizagem que se pretende em contextos educacionais, com a simplificação somativa, disciplinar, fragmentada, pontual, controladora e limitante? Para Fazenda (2005, p. 86), "a avaliação em uma sala de aula interdisciplinar acaba por transgredir todas as regras de controle costumeiro utilizadas". Hoffmann (2005), por sua vez, admite que o exercício classificatório e burocrático da avaliação é típico da descontinuidade, da segmentação e da parcelização do conhecimento. Em Santos (2006), encontramos a idéia de que a avaliação da aprendizagem é uma tarefa complexa, já que precisa considerar a trajetória e os perfis sociocognitivo e político- cultural dos estudantes. Para esta autora, as estratégias avaliativas devem estar situadas em um contexto de formação, ele mesmo um corolário da condição complexa do conhecimento contemporâneo. 
A estratégia avaliativa de múltiplas dimensões deve, também, tentar dar conta, no âmbito educacional e na esfera das interfaces deste âmbito com o mundo, de outra ocorrência, que Morin $(2001 a$, p. 16) chama de "expansão descontrolada do saber", que ocorre pelo fato de estarmos "afogados em informações", às quais classifica como "parcelas dispersas do saber", cabendo ao conhecimento a tarefa de organizá-las. Ainda aqui, a interdisciplinaridade parece adequada como filosofia e como práxis, à medida que consolida o caráter complexo do conhecimento e suas diferenças em relação às fragmentações representadas pelos dados e pelas informações. Sobre a pretensão fragmentadora, disciplinar e tecnicista de tornar sinônimos dado, informação e conhecimento, argumenta Setzer que um dado seria "uma sequência de símbolos quantificados ou quantificáveis. Portanto, um texto é um dado [...]. Também são dados imagens, sons e animação [...]. Como são símbolos quantificáveis, dados podem obviamente ser armazenados em um computador e processados por ele" (SETZER, 1999). Desta forma, "não é possivel processar informação diretamente em um computador. Para isso é necessário reduzi-la a dados". 0 conhecimento, entretanto, não é passivel de semelhante redução, sob pena de 'transformar-se', justamente, em informação. De acordo com o autor mencionado, "associamos informação à semântica; conhecimento está associado com pragmática, isto é, relaciona-se com alguma coisa existente no 'mundo real' do qual temos uma experiência direta" (SETZER, 1999).

Esta tentativa fragmentadora é apontada também por KURZ (2002):

Elucidativo é talvez o fato de que o conceito da 'sociedade do conhecimento' esteja sendo usado mais ou menos como sinônimo do de 'sociedade da informação'. Vivemos numa sociedade do conhecimento porque somos soterrados por informações. Nunca antes houve tanta informação sendo transmitida por tantos meios ao mesmo tempo. Mas esse dilúvio de informações é de fato idêntico a conhecimento? Estamos informados sobre o caráter da informação? Conhecemos afinal que tipo de conhecimento é esse?Na verdade o conceito de informação não é, de modo nenhum, abarcado por uma compreensão bem elaborada do conhecimento. 0 significado de "informação" é tomado num sentido muito mais amplo e refere-se também a procedimentos mecânicos. 0 som de uma buzina, a mensagem automática da próxima estação do metrô, a campainha de um despertador, o panorama do noticiário na TV, o alto-falante do supermercado, as oscilações da Bolsa, a previsão do tempo... tudo isso são informações, e poderíamos continuar a lista infinitamente. [...] Claro que se trata de conhecimento, também, mas de um tipo muito trivial. 
Para Frigotto (1995), em sua abordagem essencialmente dialética, a interdisciplinaridade se impõe no campo da educação como necessidade e como problema, mais até do que como método de investigação ou como técnica didática.

Esta necessidade, no âmbito das ciências sociais e na educação, segundo o autor, "decorre da própria forma de o homem produzir-se enquanto sujeito e objeto do conhecimento social". Adverte o mesmo autor, entretanto, que semelhante característica não se estabelece sem a superação da fragmentação e da lógica fenomênica pura e simples, nem se for mantido o que chama de "reducionismo estruturalista que abandona o plano discursivo" (FRIGOTTO, 1995, p. 28).

A necessidade de interdisciplinaridade na produção do conhecimento funda-se no caráter dialético da realidade social que é, ao mesmo tempo, una e diversa e na natureza intersubjetiva de sua apreensão. 0 caráter uno e diverso da realidade social nos impõe distinguir os limites do objeto investigado. Delimitar um objeto para investigação não é fragmentá-lo, ou limitá-lo arbitrariamente. Ou seja, se o processo de conhecimento nos impõe a delimitação de determinado problema, isto não significa que tenhamos que abandonar as múltiplas determinações que o constituem. E, neste sentido, mesmo delimitado, um fato teima em não perder o tecido da totalidade de que faz parte indissociável (FRIGOTTO, 1995, p. 27).

Mas esta não é uma tarefa fácil. Os contextos educacionais e sociais em geral possuem caráter complexo e histórico, e os indivíduos participantes deste cenário têm, cada um, suas limitações. Para o autor supramencionado, é necessário abandonar o tratamento da questão interdisciplinar "sob uma ótica fenomênica, abstrata e arbitrária", o que transformaria a interdisciplinaridade em uma espécie de panacéia didática, "capaz de integrar, reunir as dimensões particulares dos diferentes campos científicos ou dos diferentes saberes numa totalidade harmônica" (FRIGOTTO, 1995, p. 38). No lugar destas práticas, o autor propõe que, na pesquisa ou no trabalho pedagógico, "as concepções de realidade, conhecimento e os pressupostos e categorias de análise sejam criticamente explicitados" (FRIGOTTO, 1995, p. 45).

No âmbito da educação, Fazenda (2005) vê a reconceitualização das disciplinas em função da interdisciplinaridade. Para a autora, ainda é necessário estabelecer interações entre as diversas disciplinas como marca fundamental da interdisciplinaridade. Menciona, também, a provisoriedade do conceito de disciplina, que poderia ser substituída, em seu âmbito, pelo que chamou de "disciplinaridade interdisciplinar". Para autora, então, existe a possibilidade de construir uma "didática interdisciplinar", desde que aqueles que se integrem a esta intenção percebam-se interdisciplinares, e que adotem uma postura de intervenção, no âmbito e no nivel formal de educação em que se encontrem, que considere os saberes, práticas e organizações historicamente consolidadas. Acrescenta a autora: 
A construção de uma didática interdisciplinar baseia-se na possibilidade de efetivação de trocas intersubjetivas. Neste sentido, o papel e a postura do profissional de ensino que procure promover qualquer tipo de intervenção junto aos professores, tendo em vista a construção de uma didática transformadora ou interdisciplinar, deverão promover essa possibilidade de trocas, estimular o autoconhecimento sobre a prática de cada um e contribuir para a ampliação da leitura de aspectos não desvendados das práticas cotidianas (FAZENDA, 2005, p. 79).

E o professor que auxilia na construção, vivencia e aplica esta didática tem características peculiares, que corroboram os conceitos até aqui elencados sobre a prática interdisciplinar. Na visão de Fazenda (2005, p. 31), este professor "traz em si um gosto especial por conhecer e pesquisar, possui um alto grau de comprometimento diferenciado com seus alunos, ousa novas técnicas e procedimentos de ensino [...]". Em tudo, então, para o professor e demais profissionais envolvidos com o ensino, resta o trabalho interdisciplinar na forma de ação e não como categoria de conhecimento.

Para Torres e Bochniak (2006), a interdisciplinaridade é uma atitude de superação em relação às abordagens fragmentadas e/ou dicotômicas, que ocorre sem a desconsideração das múltiplas dimensões da realidade e sem a anulação de quaisquer identidades próprias das disciplinas. É uma prática que busca romper com as visões fragmentárias existentes no plano pessoal, ou na visão das pessoas em relação ao mundo e à realidade.

Assim, o caráter multidimensional da avaliação da aprendizagem é aquele que contempla, segundo os teóricos supramencionados, o próprio caráter multidimensional do conhecimento pertinente, em suas múltiplas formas, conexões e contextos, de modo a situar-se para além da simplificação e no âmbito da complexidade. Desta forma, a multidimensionalidade na avaliação em AVA considera que a construção da aprendizagem se dá em contextos com interações complexas, no âmbito da interdisciplinaridade, não dispensando a colaboração e a flexibilidade no planejamento como meios de potencializar as aprendizagens individuais e coletivas, considerando as trajetórias das pessoas e dos grupos.

\section{Aportes metodológicos}

Este é um trabalho sobre o uso da avaliação multidimensional em contextos virtuais de ensino-aprendizagem. A experiência relatada neste artigo tem por pano de fundo um curso de especialização em Design Instrucional (DI) para Educação On-line, oferecido pela Universidade Federal de Juiz de Fora (UFJF) em parceria com a SITE Educacional ${ }^{3}$. 0 curso é constituido por dez disciplinas on-line, além de uma disciplina presencial, chamada de "Seminários de DI", totalizando 380 horas de atividades. 
1. Conceitos, abrangência da atuação e aplicações do Design Instrucional no ensino on-line

2. Uso de ferramentas em EAD on-line

3. Abordagens pedagógicas e DI

4. Metodologia e análise do processo de comunicação

5. Planejamento e DI

6. Construção de textos e hipertextos

7. Processo de Criação I

8. Processo de Criação II

9. DI e o acompanhamento e implementação de cursos on-line

10. Avaliação

Quadro 1 - Disciplinas on-line do curso.

As disciplinas on-line são desenvolvidas totalmente a distância, utilizando o ambiente virtual TeleEduc, enquanto a disciplina presencial prevê cinco encontros, de periodicidade bimestral. 0 diploma de Pós-Graduação Lato Sensu, em nível de Especialização, em "Design Instrucional para Educação On-line", expedido pela Universidade Federal de Juiz de Fora (UFJF), é credenciado pelo MEC, através da Portaria $n^{\circ}$. 3712, de 11 de dezembro de 2003 (BRASIL, 2003).

\section{Design instrucional}

0 termo design instrucional (DI) - ou design educacional, como prefere Almeida (2003) - merece uma descrição, em função de fornecer, de certa forma, o contexto do qual emergiram os dados da pesquisa aqui relatada. 0 DI parte da interseção de três disciplinas: educação, psicologia e comunicação. Da educação, esta área procura apropriar-se dos conceitos e teorias que explicam como se dá a aprendizagem em contextos formais ou informais. Da psicologia, busca os pressupostos sobre o aprendizado e o desenvolvimento humanos. Na comunicação, procura os elementos teóricos e práticos sobre a veiculação ótima de mensagens e a disposição das mesmas na tela quanto à usabilidade.

Autores como Jacobs (1987) e Rothwell (1996) argumentam que o design instrucional significa mais do que meramente criar formas de apropriar conteúdos. 0 DI está relacionado com o tema muito mais abrangente da análise sistemática dos problemas de performance humana, identificando as causas originais de semelhantes problemas, considerando várias soluções para equacionar as causas, e implementando as soluções de forma a minimizar as eventuais consequências imprevistas que as ações de design poderiam provocar. 
Para Willis (2000), é importante, quando do projeto de um curso a distância, a criação de um processo e o estabelecimento de uma estrutura que permita o planejamento sistemático, desenvolvimento e adaptações que tenham por base as necessidades conhecidas dos alunos e os requisitos do conteúdo, já que os participantes do curso, estudantes e professores, podem não possuir a mesma bagagem. 0 autor propõe um modelo, baseado em quatro etapas principais: design, desenvolvimento, avaliação e revisão. No estágio de design, existem, ainda, segundo o autor, três tarefas primordiais:

- Determinar a demanda por instrução, considerando que dados indicam esta necessidade, que fatores conduzem à necessidade de instrução e que experiências anteriores indicam que o curso que está sendo planejado efetivamente atinge esta necessidade;

- analisar o público-alvo para entender melhor os potenciais aprendizes, considerando a idade dos mesmos, o lastro cultural que possuem, as experiências anteriores, os interesses e o nível educacional que obtiveram até então;

- estabelecer objetivos instrucionais, com base na natureza do problema assim como as necessidades e características dos estudantes.

\section{Pesquisa qualitativa}

Com relação à abordagem metodológica, a opção pela pesquisa qualitativa mostrou-se a mais adequada, adotando-se, também, a análise de conteúdos como principal técnica de análise. As questões que surgiam e que causavam o impulso em direção da busca de sentidos e elucidações tinham caráter particular, não podiam ser generalizadas em torno de quantidades sempre aplicáveis e de percentuais infaliveis, pedindo, antes, descrições que apontassem na busca das respostas direcionadas pelo problema e pelas hipóteses substantivas. Esta asserção corrobora o ponto de vista de Minayo (1994, p. 21), segundo a qual "a pesquisa qualitativa responde a questões muito particulares". Para a autora, esta abordagem "trabalha com o universo de significados, motivos, aspirações, crenças, valores e atitudes, o que corresponde a um espaço mais profundo das relações, dos processos e dos fenômenos que não podem ser reduzidos à operacionalização de variáveis" (MINAYO, 1994, p. 21).

As categorias de análise, construídas ao longo da investigação, eram as seguintes:

- avaliação, colaboração e superação da lógica do exame: multidimensionalidade e complexidade;

- avaliação: acompanhamento das trajetórias individuais;

- avaliação: tempo e espaço.

Os dados analisados nesta investigação tem como fonte a décima disciplina on-line do curso, cujo tema era "Avaliação". 0 objetivo principal desta disciplina era o de oferecer ao profissional encarregado das ações de DI uma idéia ampla sobre avaliação em seus 
diversos aspectos, com foco nas ações avaliativas passíveis de implementação em cursos on-line a distância oferecidos em AVAs. A proposta pretendia oferecer aos profissionais em formação, também, um debate sobre a superação da lógica classificatória predominante em processos de avaliação da aprendizagem, com base em Luckesi (2001) e Hoffmann (2005), substituindo-a por uma abordagem multidimensional, capaz de considerar o individuo que aprende em todos os momentos e aspectos, processualmente.

\section{Os sujeitos da pesquisa}

Para admissão ao curso de especialização em Design Instrucional para Educação On-Line, a Universidade Federal de Juiz de Fora (UFJF) e a SITE Educacional procederam à seleção dos inscritos através de análise do currículo e de exame dos documentos. Todos os candidatos deveriam ser portadores de diploma de ensino superior relativo a curso reconhecido pelo MEC, em qualquer área do conhecimento, sendo obrigatória a apresentação deste documento e do histórico do curso.

Em relação aos participantes que cursaram a disciplina "Avaliação", no âmbito da qual esta pesquisa foi realizada, verificou-se um quadro de formação acadêmica bastante diversificado, tanto no que diz respeito à área de conhecimento da(s) graduação(ões) de cada um dos participantes, quanto em relação à formação posterior por eles já consolidada (especializações, mestrado ou doutorado). Ao todo, eram vinte os participantes, provenientes de diversos locais do Brasil e do exterior.

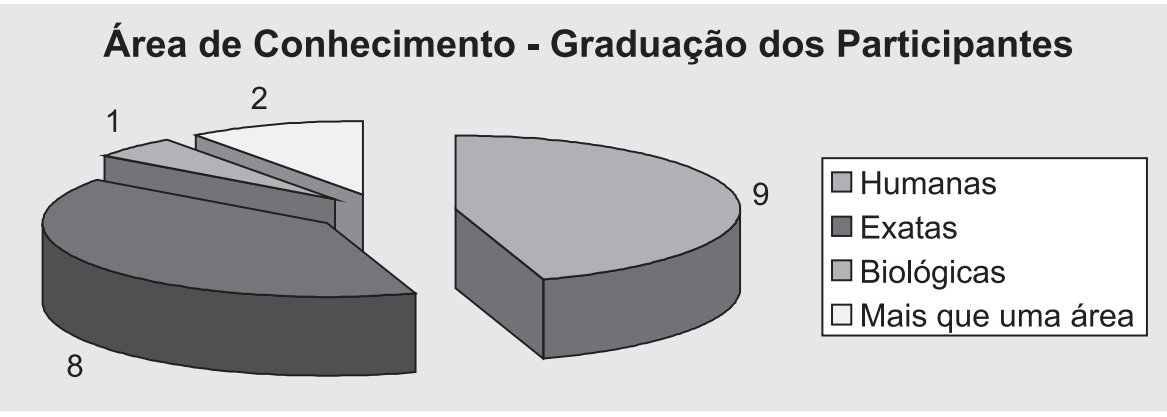

Gráfico 1 - Número de participantes/área do conhecimento. Fonte: UFJF e SITE Educacional (2008).

Nos perfis pessoais, preenchidos na inscrição ${ }^{4}$, os candidatos declararam que, entre outros motivos, buscavam um curso que os amparassem na ampliação de conhecimentos na área de design instrucional de cursos on-line através de uma titulação reconhecida pelo MEC (ou seja, com valor legal). Outro motivo largamente alegado foi o reco- 
nhecimento pelo mercado de trabalho, através de um título valioso e sério. De forma mais específica, a relação direta com a atuação profissional foi o motivo mais alegado. Além disso, a maior parte dos alunos selecionados já possuía alguma experiência com DI.

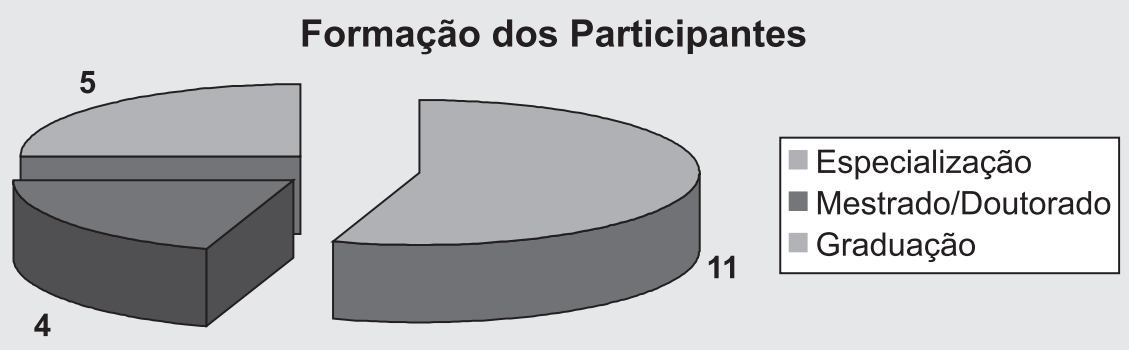

Gráfico 2 - Nível de formação dos participantes.

Fonte: UFJF e SITE Educacional (2008).

Com relação ao exercício profissional, a maior parte dos alunos selecionados tinham atuações ligadas ao próprio design instrucional, às funções relacionadas ao ensino a distância (webdesigner, gestão) ou à docência nas diversas modalidades ${ }^{5}$, incluindo neste último grupo aqueles que desempenham também atividades de coordenação pedagógica. Além disso, a maior parte dos candidatos selecionados para o curso pretendia atuar como DI na educação superior e/ou na educação corporativa, ainda que alguns alunos declarassem pretender atuar também nos outros níveis. 0 mesmo pode ser observado em relação à atuação como Dl's que os alunos já tinham no momento da inscrição.

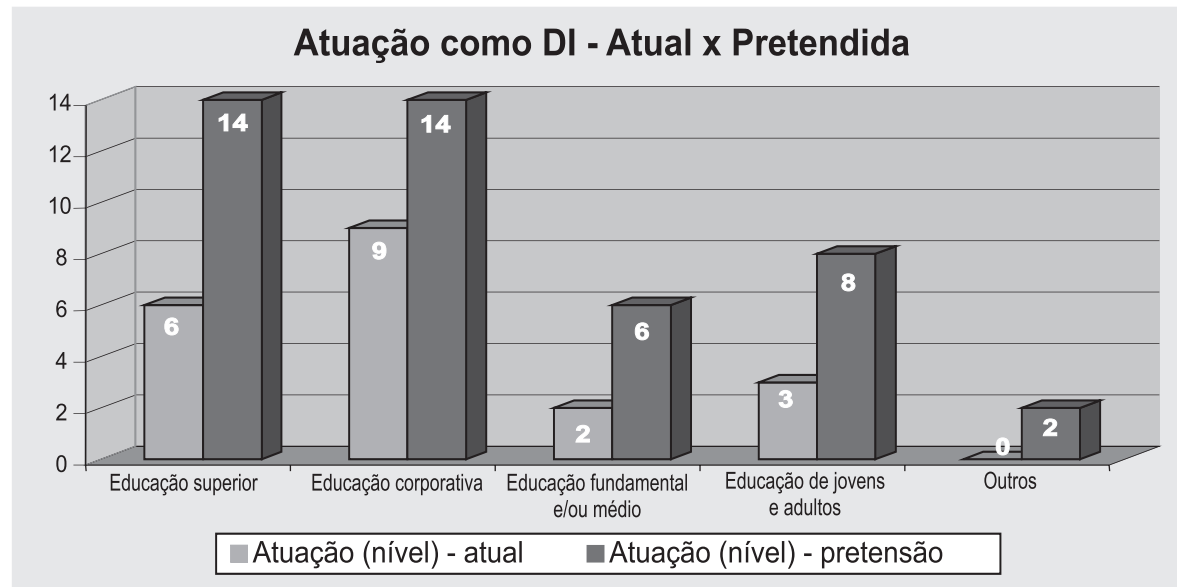

Gráfico 3 - Atuação dos participantes como DI (atual x pretendida). Fonte: UFJF e SITE Educacional (2008). 
Com relação à velocidade de conexão, pode-se constatar que a maioria dos participantes dispunha de acesso do tipo banda larga (mais veloz), ainda que alguns alunos usassem a linha discada parte do tempo (em casa, por exemplo). Apenas um candidato selecionado para o curso usava exclusivamente a linha discada.

\section{Análise dos dados}

A disciplina "Avaliação" foi dividida em quatro semanas, cada qual contendo um tema distinto. Os temas semanais, as atividades, as interações, bem como outras informações de relevo, podiam ser acessados por todos os participantes do curso em documentos próprios, disponíveis no AVA. 0 tema da terceira semana, cujo desenvolvimento é tratado neste artigo, era "Reorientação no processo: avaliação, memória e acompanhamento em cursos on-line". Os destaques deste relato ficam, então, por conta das atividades propostas para o tratamento do tema, destinadas a incentivar a reflexão, o debate, a colaboração e um processo de construção de aprendizagem passivel de ser avaliado multidimensionalmente (OLIVEIRA, 2007).

A semana três do curso, tratada neste relato, versava sobre as funções de acompanhamento que podiam ser atribuídas à avaliação. Sobre este tema, foi proposta uma leitura, a partir da qual se propunha uma reflexão sobre o aspecto formativo das avaliações e o papel do DI. Como nas semanas anteriores, o tema poderia ser tratado em uma discussão aberta no fórum. Entretanto, em que pese o fato de este espaço ter produzido mensagens, foi o chat a principal interface utilizada nesta oportunidade. Não que o mesmo não tivesse relevância nas outras jornadas - foi bastante usado no entendimento das tarefas grupais e na organização das mesmas. É que havia uma tarefa específica proposta para os mesmos grupos formados na semana dois: realizar um chat relâmpago sobre o tema da semana, produzindo, depois, um texto coletivo baseado nas interações ocorridas nesta ocasião.

Um chat relâmpago pode ser conduzido de diversas formas, mas consiste, geralmente, em uma troca de opiniões bastante rápida entre duas ou mais pessoas, tendo um tema por base. Na tarefa proposta, cada grupo, que tinha de três a seis pessoas ${ }^{6}$, recebeu o tema "DI e avaliação" e devia, com base nas leituras já realizadas, nas experiências pessoais, nas construções coletivas prévias, produzir a base para um texto de autoria coletiva. A tarefa prescrevia apenas uma limitação: havia uma ordem, ou seja, cada participante deveria manifestar-se na sua vez, sendo que, no caso, era permitido apenas construir uma frase por intervenção.

60 número de componentes de cada grupo obedeceu às demandas dos próprios participantes, levando em conta itens como disponibilidade para atividades sincronas, ritmo de trabalho, afinidades teóricas, entre outros. Decidi não prescrever um tamanho ideal e obrigatório para os grupos. 
A ideia central era a de que, em no máximo quarenta minutos, todos os participantes fizessem suas intervenções, colaborando para a construção coletiva do conhecimento. A participação, neste caso, seria dividida de forma semeIhante entre todos. Claro que, como os perfis eram muito diversos, as intervenções individuais corriam o risco de resultarem muito diferentes, quanto à forma e à relevância. Em função disto, negociamos pelo uso das postagens no fórum e as trocas realizadas via e-mail como formas de completar os textos e melhor organizá-los. A estrutura dos mesmos, no entanto, permaneceu sendo aquela dada pelas trocas ocorridas nos chats.

Nos momentos anteriores da disciplina, diversos chats 'livres' já haviam ocorrido. Os mesmos estavam por conta da autonomia dos participantes em prover elementos de troca e colaboração, servindo os mesmos também, através de suas transcrições, às análises da avaliação multidimensional da aprendizagem. Como característica destes outros momentos síncronos de interação, percebi que a menor organização favorecia as trocas informais e as amenidades, permeando os assuntos tratados de forma mais relacionada aos estudos da disciplina. Foram momentos muito importantes para a integração dos grupos, para os debates e reflexões, para a organização de aspectos de outras tarefas, mas demandavam tempos os quais nem todos dispunham. Assim, a adesão era menor e a participação, desigual. 0 chat relâmpago contribuiu, ao aumentar (mas não nivelar) a distribuição das intervenções entre todos, as possibilidades de avaliação individualizadas, no que diz respeito aos elementos propostos para o estudo, em um ambiente de menor dispersão e maior organização. Foi uma forma de, na avaliação, ganhar outro elemento de análise, que se somou ao chat livre.

A transcrição desta atividade, que era solicitada como parte da tarefa, a ser disponibilizada no portfólio grupal, revelou interessantes características de autoorganização nos grupos, como também outras, relacionadas aos diferentes perfis e níveis de proatividade dos participantes. Acompanhando a transcrição, foi possivel, do ponto de vista da avaliação, perceber o processo de construção do texto, entendendo como cada um se colocava, a relevância de suas reflexões e a disposição em trabalhar de forma colaborativa. Aliás, esta colaboração se completaria mais tarde, no momento em que todos voltavam a intervir, de uma forma mais livre, para estruturar o texto, dando-Ihe forma, fazendo a revisão, agregando outros elementos para dar 'liga' à produção.

Cada uma das transcrições tinha cerca de 20 a 30 páginas, o que não permite reproduzir nenhuma delas integralmente. No entanto, penso que alguns pontos podem ser destacados, de forma mais sintética. Uso, para tanto, os dados do chats relâmpago dos grupos $\mathrm{A}$ e $\mathrm{B}$. 
Quanto à organização das falas na atividade (Grupo A)

\begin{tabular}{|l|l|}
\hline Aluno 1 & Definindo a ordem de posicionamento. Como faremos? \\
\hline Aluno 2 & Estabeleçamos uma ordem. \\
\hline Aluno 1 & Ordem alfabética? \\
\hline Aluno 1 & Ou não? \\
\hline Aluno 2 & Alguém se habilita a começar? \\
\hline Aluno 4 & Não. \\
\hline Aluno 3 & Entendi que seria simultâneo. Como o One Minute Paper, lembram? \\
\hline Aluno 1 & Posso começar. \\
\hline Aluno 2 & $\begin{array}{l}\text { Vamos traçar primeiro as estratégias e só depois marcamos } \\
\text { o tempo. 0 que acham? }\end{array}$ \\
\hline Aluno 1 & Entendi que deveriamos estabelecer uma ordem, não? \\
\hline Aluno 1 & Certo. \\
\hline Aluno 2 & Não, Aluno 3, tem que haver uma ordem. \\
\hline Aluno 4 & Tudo bem. \\
\hline Aluno 2 & Fala um de cada vez. \\
\hline Aluno 1 & Aluno 3 disse que não é preciso definir a ordem antes. \\
\hline Aluno 1 & Posso começar e vocês vão-se posicionando. \\
\hline Aluno 1 & Um após outro. \\
\hline Aluno 2 & $\begin{array}{l}\text { Precisa sim, tanto é que na agenda o Gerson colocou quem cada um } \\
\text { fala na sua vez; caso contrário perde a vez... }\end{array}$ \\
\hline Aluno 4 & Sim. \\
\hline Aluno 2 & É preciso sempre manter a ordem, certo? \\
\hline Aluno 3 & Então, ok. \\
\hline Aluno 1 & Então quem será o 2 ${ }^{\circ}$ ? \\
\hline Aluno 2 & Eu. \\
\hline Aluno 1 & 3a? \\
\hline Aluno 3 & Posso ser eu, caso o Aluno 4 não tenha preferência. \\
\hline Aluno 4 & Eu o ultimo. \\
\hline Aluno 1 & Então podemos começar. \\
\hline Aluno 2 & Então, vamos deixar claro o seguinte. \\
\hline Aluno 2 & $\begin{array}{l}\text { Depois de cada colocação é dado um tempinho para o próxi- } \\
\text { mo se colocar; caso ele fique mudo (por qualquer razão) o } \\
\text { próximo da fila fala. }\end{array}$ \\
\hline Aluno 4 & Tá. \\
\hline Aluno 1 & Aluno 2, todos devem falar e cuidar de ser objetivos e rápidos. \\
\hline Aluno 2 & Ok. \\
\hline Aluno 1 & Mesmo que para dizer que não tem opinião. \\
\hline Aluno 1 & Se a pessoa não tiver o que dizer, passe a bola. \\
\hline
\end{tabular}


A transcrição indica que todos tiveram alguma intervenção na organização das falas. As regras adotadas foram aquelas sugeridas na agenda da atividade. A ordem de intervenção foi definida em acordo entre todos, cada um assumindo uma posição que Ihe parecia mais adequada. Após este período, começou o chat efetivamente.

\section{Quanto à realização do chat - Grupo A}

\begin{tabular}{|c|c|}
\hline Aluno 1 & $\begin{array}{l}\text { A avaliação formativa visa basicamente a reorientação e o acom- } \\
\text { panhamento da disciplina, do curso.Relaciona-se à construção da } \\
\text { aprendizagem em si, mas também, de processos, ambientes, cursos, } \\
\text { etc. } 0 \text { foco na avaliação formativa é aquele que aprende. Daí a } \\
\text { atitude de observar quem usa o "produto curso", o aluno, é essen- } \\
\text { cial, BÁSICA, nesse processo. Mais que professores, tutores, insti- } \\
\text { tuições. }\end{array}$ \\
\hline Aluno 2 & $\begin{array}{l}\text { Tem como propósito melhorar a aprendizagem individual ou a qualida- } \\
\text { de de alguns aspectos do curso }\end{array}$ \\
\hline Aluno 3 & $\begin{array}{l}\text { Da leitura disponibilizada... A avaliação formativa é tipicamente } \\
\text { utilizada para reorientação e acompanhamento. É mais atenta aos } \\
\text { detalhes, procura focar pontos específicos, individuais, sempre que } \\
\text { possível. }\end{array}$ \\
\hline Aluno 4 & É também uma forma de regulação. \\
\hline Aluno 1 & $\begin{array}{l}\text { Possibilita a identificação de indicadores para a manutenção ou } \\
\text { correção de processos estruturais. }\end{array}$ \\
\hline Aluno 2 & $\begin{array}{l}\text { É um dos recursos que contribuem para a efetividade de uma proposta } \\
\text { pedagógica que tenha o sucesso de seus alunos como um de seus desafios. }\end{array}$ \\
\hline Aluno 3 & $\begin{array}{l}\text { Admite a possibilidade de reescrever pontos do planejamento para } \\
\text { que um processo de aprendizagem, um ambiente ou um curso pos- } \\
\text { sam fornecer elementos que permitam aos gestores aproximar os } \\
\text { objetivos das trajetórias dos participantes. Gera retornos consis- } \\
\text { tentes da participação de cada um, de forma que cada um dos } \\
\text { envolvidos (por exemplo, alunos e professores) possa refletir sobre } \\
\text { sua performance, }\end{array}$ \\
\hline Aluno 4 & Esta avaliação põe o aluno no centro do processo, em primeiro plano. \\
\hline Aluno 2 & $\begin{array}{l}\text { Possibilita a continuidade do trabalho pedagógico e o respeito ao rit- } \\
\text { mo de aprendizagem de cada aluno. Favorece o diálogo constante en- } \\
\text { tre as atividades didáticas e a aprendizagem. }\end{array}$ \\
\hline Aluno 1 & $\begin{array}{l}\text { Serve para monitorar indicadores de qualidade estabelecidos no plane- } \\
\text { jamento para a implementação do curso. }\end{array}$ \\
\hline Aluno 2 & A autoavaliação é importante neste processo. \\
\hline Aluno 3 & $\begin{array}{l}\text { Utiliza a avaliação formativa para determinar mudanças possíveis em pro- } \\
\text { cessos e procedimentos relacionados ao curso (objetivos, cronograma,material } \\
\text { didático, atuação do professor/tutor, programadores designers gráficos, re- } \\
\text { cursos midiáticos, recursos financeiros e custos, etc.) }\end{array}$ \\
\hline Aluno 4 & Passo \\
\hline
\end{tabular}


(Continuação)

\begin{tabular}{|c|c|}
\hline Aluno 1 & $\begin{array}{l}\text { Para identificar oportunidades de correções e melhorias visando não só } \\
\text { à "manutenção" da qualidade do curso durante seu desenvolvimento e/ } \\
\text { ou para a reedição do curso. }\end{array}$ \\
\hline Aluno 2 & Passo \\
\hline Aluno 3 & $\begin{array}{l}\text { Fundamental para o sucesso do curso.Deve servir como incentivo e } \\
\text { acompanhamento do progresso do aluno. }\end{array}$ \\
\hline Aluno 4 & Passo \\
\hline Aluno 1 & $\begin{array}{l}\text { Buscar feedback não se limita a levantar opiniões. } 0 \text { feedback deve } \\
\text { resultar de observação, reflexão, diálogo e trocas relacionadas a toda a } \\
\text { estrutura de cursos on-line e de todos os personagens que nele atuam. }\end{array}$ \\
\hline Aluno 3 & Desculpem a antecipação \\
\hline Aluno 2 & $\begin{array}{l}\text { A própria avaliação formal pode servir de feedback para a melhoria do } \\
\text { curso, favorecendo a aprendizagem. }\end{array}$ \\
\hline Aluno 3 & $\begin{array}{l}\text { Fundamental para o sucesso do curso. Deve servir como incentivo e } \\
\text { acompanhamento do progresso do aluno. }\end{array}$ \\
\hline Aluno 4 & Passo \\
\hline Aluno 1 & $\begin{array}{l}\text { Fóruns, chats, e-mails, portfólios, diários de bordo, entre são espa- } \\
\text { ços que podem servir de ferramentas para o feedback. }\end{array}$ \\
\hline Aluno 2 & E devem ser considerados em sua totalidade pelo DI, orientando suas ações. \\
\hline Aluno 3 & $\begin{array}{l}\text { Deve ser usado para acompanhar o desempenho escolar de cada } \\
\text { aluno, identificando aspectos que demandem atenção especial. }\end{array}$ \\
\hline Aluno 4 & Passo \\
\hline Aluno 1 & $\begin{array}{l}\text { Monitorar indicadores de qualidade estabelecidos no planejamento } \\
\text { para a implementação do curso.Determinar mudanças possiveis em } \\
\text { processos e procedimentos relacionados ao curso (atuação do profes- } \\
\text { sor/ programadores, designers, recursos midiáticos, recursos finan- } \\
\text { ceiros e custos, etc.). (Re)definir processos e procedimentos para ma- } \\
\text { nutenção e/ou ações corretivas.(Re)definir processos e procedimentos }\end{array}$ \\
\hline Aluno 2 & $\begin{array}{l}\text { Ações do DI: elaboração da proposta - organização das atividades, se- } \\
\text { quenciamento dos conteúdos e preparação dos instrumentos de avali- } \\
\text { ação, em conjunto com o professor conteudista; programação de re- } \\
\text { cursos e atividades virtuais... }\end{array}$ \\
\hline Aluno 3 & $\begin{array}{l}\text { Utiliza a avaliação diagnóstica para monitorar indicadores de qua- } \\
\text { lidade estabelecidos no planejamento para a implementação do } \\
\text { curso. Utiliza a avaliação formativa para determinar mudanças } \\
\text { possíveis em processos e procedimentos relacionados ao curso (ob- } \\
\text { jetivos, cronograma, material didático, atuação do professor/tutor, } \\
\text { programadores designers gráficos, recursos midiáticos, }\end{array}$ \\
\hline Aluno 3 & $\begin{array}{l}\text { Recursos financeiros e custos, etc.) Utiliza a avaliação somativa para rede- } \\
\text { finir processos e procedimentos para manutenção e/ou ações corretivas. }\end{array}$ \\
\hline Aluno 1 & $\begin{array}{l}\text { Em tempo, pessoal: essas ações são as que devem ocorrer DURANTE } \\
\text { o processo. }\end{array}$ \\
\hline
\end{tabular}


(Continuação)

\begin{tabular}{|l|l|}
\hline Aluno 1 & $\begin{array}{l}\text { "Descobrir como, de que forma, com quais instrumentos aquele grupo } \\
\text { específico de pessoas aprende mais e melhor, além de não ter menor } \\
\text { importância descobrir porque determinadas pessoas têm maior difi- } \\
\text { culdade na construção dos conhecimentos (ou mesmo na memoriza- } \\
\text { ção) em certas circunstâncias". }\end{array}$ \\
\hline Aluno 2 & $\begin{array}{l}\text { Importante frisar que um requisito relevante para o DI é ser um } \\
\text { especialista em educação, com visão estendida para outras áreas } \\
\text { relacionadas. Concordam? }\end{array}$ \\
\hline Aluno 1 & Para fechar... Alguém tem algo mais? \\
\hline Aluno 4 & Não. \\
\hline Aluno 3 & $\begin{array}{l}\text { Redefinir processos e procedimentos para manutenção e/ou ações cor- } \\
\text { retivas na reedição do curso. }\end{array}$ \\
\hline Aluno 1 & Fechamos em 28 min! \\
\hline
\end{tabular}

Nota-se que as intenções da tarefa foram alcançadas, uma vez que é clara a colaboração estabelecida na construção das bases do texto. É claro que, quanto a este ponto, a intensidade da participação dos alunos foi diferente, principalmente no que se refere a Aluno 4 - trago esta discussão no final deste trabalho. 


\section{Quanto às tarefas posteriores ao chat - Grupo A}

\begin{tabular}{|l|l|}
\hline Aluno 1 & Agora, vamos definir a próxima etapa. \\
\hline Aluno 4 & Ótimo! \\
\hline Aluno 2 & "Amarração" das idéias e criação do texto. \\
\hline Aluno 1 & É preciso criar um texto a partir do aqui registrado. \\
\hline Aluno 1 & Quem, faz? \\
\hline Aluno 2 & Posso fazer. \\
\hline Aluno 1 & Certo. \\
\hline Aluno 3 & Ok, Aluno 2. \\
\hline Aluno 4 & Legal! \\
\hline Aluno 1 & Depois a revisão. Posso fazer. \\
\hline Aluno 2 & $\begin{array}{l}\text { Mas o que acham? Um texto dividido em } 4 \text { partes ou uma } \\
\text { parte só? }\end{array}$ \\
\hline Aluno 1 & Cuidado, Aluno 2, pois há dados fora de ordem... \\
\hline Aluno 3 & Ok, Aluno 1. \\
\hline Aluno 1 & E alguns em desacordo com o proposto... \\
\hline Aluno 1 & Uma parte só. \\
\hline Aluno 1 & Com quatro parágrafos. \\
\hline Aluno 2 & $\begin{array}{l}\text { Certo. Vou tentar amarrar tudo amanhã de manhã até a } \\
\text { hora do almoço e coloco no correio do TeleEduc para vocês } \\
\text { opinarem e mexerem... }\end{array}$ \\
\hline Aluno 1 & Somente poderei acessar à noite... \\
\hline Aluno 1 & Posto à noite mesmo para validação até quinta-feira. \\
\hline Aluno 2 & Ok. Á tarde, posto no correio e vocês mandam brasa... \\
\hline Aluno 4 & Ok. \\
\hline Aluno 3 & Ok. \\
\hline Aluno 1 & $\begin{array}{l}\text { Ouem pode postar este arquivo no correio e no Portfólio? } \\
\text { Aluno 3? }\end{array}$ \\
\hline Aluno 3 & Salvo imprevistos... Posso sim! \\
\hline Aluno 1 & $\begin{array}{l}\text { Certo. Pode fazê-lo amanhã, pois Aluno 2 tem o chat desde } \\
\text { o início. }\end{array}$ \\
\hline Aluno 1 & Então pessoal, até a próxima!! \\
\hline
\end{tabular}

As tarefas 'pós-chat' completaram, então, em caráter cooperativo, a tarefa colaborativa anterior. 0 texto foi postado no prazo, contendo as considerações de todos os participantes - inclusive Aluno 4 - e trouxe, em seu conteúdo, uma síntese bastante completa das discussões, dos fóruns e do texto da semana três. 0 mesmo ocorreu com os outros cinco grupos, os quais trabalharam de forma muito semeIhante, trazendo a cooperação para completar a colaboração, no momento seguinte ao chat relâmpago. 


\section{Características gerais do chat relâmpago realizado pelo Grupo B}

0 grupo $B$ era composto por seis membros. $A$ organização das falas foi muito semelhante àquela encontrada pelo grupo $A$, ou seja, todos sugeriram e acabaram encontrando um posicionamento mutuamente confortável, com um dos participantes assumindo o papel de organizador das falas. Também como no grupo anteriormente descrito, o tempo começou a ser marcado no momento em que as interações ligadas ao assunto começaram a surgir. A diferença, neste ponto, é que a totalidade dos quarenta minutos destinados à tarefa foi utilizada, o que pode ser explicado pela maior uniformidade das intervenções significativas. Descontando as falas destinadas à organização e à distribuição de tarefas posteriores, todos os seis membros fizeram oito intervenções cada, todas de caráter significativo.

Aqui, a transcrição de algumas das trocas havidas neste momento é compensadora pela riqueza da produção e pelas possibilidades avaliativas presentes, que envolveram olhares sobre a preparação que cada um realizou para a atividade, sobre a relevância das intervenções, sobre a ligação de cada fala com o assunto discutido e sobre o nivel de colaboração alcançado na construção do conhecimento.

\begin{tabular}{|c|c|}
\hline Aluno 9 & $\begin{array}{l}\text { A avaliação formativa não tem como objetivo classificar ou sele- } \\
\text { cionar. Fundamenta-se nos processos de aprendizagem, em seus } \\
\text { aspectos cognitivos, afetivos e relacionais; fundamenta-se em } \\
\text { aprendizagens significativas e funcionais que se aplicam em di- } \\
\text { versos contextos e se atualizam o quanto for preciso para que se } \\
\text { continue a aprender. }\end{array}$ \\
\hline Aluno 6 & Agora é você, Aluno 7. \\
\hline Aluno 7 & $\begin{array}{l}\text { A avaliação formativa é utilizada para reorientar e acompanhar. É } \\
\text { mais atenta a detalhes. }\end{array}$ \\
\hline Aluno 6 & gora é você, Aluno 10! \\
\hline Aluno 10 & $\begin{array}{l}\text { A avaliação formativa solicita um acompanhamento criterioso do } \\
\text { avaliador em relação ao avaliado, além de uma disposição de par- } \\
\text { ticipar de um processo interativo de troca de informações, onde o } \\
\text { aprendizado acontece dos dois lados. Neste processo de avaliação } \\
\text { verifica-se todo o processo de ensino aprendizagem, ou seja, com } \\
\text { um olhar para quem aprendeu e um olhar também para quem } \\
\text { ensinou. }\end{array}$ \\
\hline Aluno 6 & Aluno 5, é contigo! \\
\hline Aluno 5 & $\begin{array}{l}\text { Roteiros para mídias interativas, no caso avaliação formativa, } \\
\text { podem prever pontos que podem ser reencaminhados, voltar para } \\
\text { outras rotas, ou cortando possíveis etapas, na busca de alcançar } \\
\text { o objetivo por diversos níveis, isso se dá em função das respostas } \\
\text { dos alunos por diferentes estímulos colocados ao longo do curso. }\end{array}$ \\
\hline
\end{tabular}


(Continuação)

\begin{tabular}{|c|c|}
\hline Aluno 6 & Aluno 8, é você! \\
\hline Aluno 8 & $\begin{array}{l}\text { A avaliação formativa é processual, continuada, o que significa que } \\
\text { sua prática acompanha o processo integralmente. As finalidades deste } \\
\text { modelo não envolvem a atribuição de nota, mas o recolhimento de } \\
\text { subsídios para que alunos e professores recebam feedbacks consisten- } \\
\text { tes sobre sua trajetória num curso. }\end{array}$ \\
\hline Aluno 6 & $\begin{array}{l}\text { A avaliação formativa não se limita ao recolhimento periódico da im- } \\
\text { pressão dos alunos sobre o andamento do curso. Ela deve estar inserida } \\
\text { em todas as atividades do curso e deve ser pautada na observação, na } \\
\text { reflexão, no diálogo e na interação. Com certeza, ela exige muito mais } \\
\text { da equipe pedagógica do que a avaliação somativa exigiria. }\end{array}$ \\
\hline Aluno 6 & Aluno 9, você de novo. \\
\hline Aluno 9 & $\begin{array}{l}\text { Na avaliação formativa, prevalecem os aspectos qualitativos sobre os } \\
\text { quantitativos. Isto é, os resultados obtidos pelo aluno durante o peri- } \\
\text { odo letivo, considerando vários aspectos, são mais importantes do } \\
\text { que simplesmente a média nas provas finais. }\end{array}$ \\
\hline Aluno 6 & Aluno 7, é você! \\
\hline Aluno 7 & $\begin{array}{l}\text { A avaliação formativa está em contato direto com o aluno. Ele é peça } \\
\text { fundamental da ação. É dele que obtemos as "reações" necessárias } \\
\text { para que possamos fazer qualquer adaptação e verificar como está } \\
\text { processando a sua aprendizagem. }\end{array}$ \\
\hline Aluno 6 & Aluno 10, tá contigo! \\
\hline Aluno 10 & $\begin{array}{l}\text { A avaliação formativa pode ser feita por ferramentas de avaliação } \\
\text { mas o acompanhamento do professor é de suma importância para } \\
\text { um resultado mais próximo do desempenho. }\end{array}$ \\
\hline Aluno 6 & Aluno 5, é você. \\
\hline Aluno 5 & $\begin{array}{l}\text { Mas na verdade este número de "rotas" não pode ser comparado a } \\
\text { um labirinto, pois a todo tempo o aluno, que é o centro do processo, } \\
\text { terá um mapa de todas estas rotas, por isso quando se retorna para } \\
\text { rever algum conceito os assuntos podem ser aclarados. }\end{array}$ \\
\hline Aluno 6 & Aluno 8, tá contigo. \\
\hline Aluno 8 & $\begin{array}{l}\text { Como nossas intervenções nessa rodada estão tratando mais de alu- } \\
\text { nos, vale ressaltar que a autonomia é uma caracteristica importante a } \\
\text { ser incentivada no aluno para garantir a avaliação formativa. Tornan- } \\
\text { do mais ativa sua participação no processo e mais ampla suas percep- } \\
\text { ções, suas possibilidades também crescem. }\end{array}$ \\
\hline Aluno 6 & $\begin{array}{l}\text { A necessidade de dedicação maior da equipe pedagógica às tarefas } \\
\text { de avaliação formativa, para acompanhar de fato o aluno, deve ser } \\
\text { prevista já no planejamento. Além disso, na medida do possível, o } \\
\text { DI deve estar envolvido nesse processo durante seu desenrolar, para } \\
\text { que possa avaliar as melhorias e ajustes necessários no curso para } \\
\text { que ele atenda às reais necessidades dos alunos. }\end{array}$ \\
\hline Aluno 6 & Aluno 9, sua vez. \\
\hline
\end{tabular}


(Continuação)

\begin{tabular}{|l|l|}
\hline Aluno 6 & Estamos no meio do chat: 20 minutos. \\
\hline Aluno 9 & $\begin{array}{l}\text { Por sua natureza ampla e pessoal, ela deve ser uma prática contextu- } \\
\text { alizada, flexivel e contínua. A avaliação formativa, entendida como } \\
\text { inserida em um projeto politico- pedagógico, postula a autonomia e a } \\
\text { cooperação como princípios básicos da educação. }\end{array}$ \\
\hline Aluno 6 & Aluno 7, manda ver. \\
\hline Aluno 7 & $\begin{array}{l}\text { Colaborar. Esta é a principal referência que temos que ter enquanto } \\
\text { formadores de cursos on-line. Colaborar na formação do aluno e ob- } \\
\text { ter dessa relação informações necessárias para o bom desenvolvimen- } \\
\text { to do processo. }\end{array}$ \\
\hline Aluno 6 & Aluno 10, vai lá. \\
\hline Aluno 10 & $\begin{array}{l}\text { A avaliação formativa é mais atenta para a reorientação e acompa- } \\
\text { nhamento, procurando detalhes e pontos especificos, algo bem per- } \\
\text { sonalizado. }\end{array}$ \\
\hline Aluno 6 & \begin{tabular}{l} 
Aluno 5, é você mesmo. \\
\hline Aluno 5
\end{tabular} $\begin{array}{l}\text { Levando em conta os "clicadores compulsivos": vão-se dar conta des- } \\
\text { ta forma de "aprender a aprender", que vai ser uma busca de um } \\
\text { melhor entendimento para estas confluências, pois o que ser quer e o } \\
\text { aprendizado consistente para cada um dos envolvidos no processo: } \\
\text { alunos, professores e gestores. }\end{array}$ \\
\hline Aluno 6 & \begin{tabular}{l} 
Aluno 8, a bola é sua. \\
\hline Aluno 8
\end{tabular} $\begin{array}{l}\text { Colaboração é a palavra chave na avaliação formativa - dividir e descen- } \\
\text { tralizar o poder antes concentrado somente na figura docente aumen- } \\
\text { ta a responsabilidade do estudante em relação ao próprio aprendizado. }\end{array}$ \\
\hline Aluno 6 & $\begin{array}{l}\text { Como o objetivo da avaliação formativa é identificar e compreender } \\
\text { os problemas de aprendizagem enfrentados pelos alunos de um curso, } \\
\text { oferecendo informações para o desenvolvimento de ações pedagó- } \\
\text { gicas que auxiliem a aprendizagem dos alunos, torna-se importan- } \\
\text { te que ela se dê de forma cooperativa, na qual alunos e equipe } \\
\text { pedagógica caminham juntos em prol de um melhor aproveitamen- } \\
\text { to do curso. }\end{array}$ \\
\hline
\end{tabular}

A leitura da transcrição da atividade do grupo $B$, trazida apenas parcialmente aqui, permite perceber que, além do texto colocado para a leitura da semana, outros referenciais foram buscados. Dentre eles, destacam-se textos de Luckesi (2001) e Hoffmann (2005), entre outros. Contextualizadas, as referências não se colocaram como meras colagens, mas completaram as falas dos próprios alunos, que se fizeram ora autores, ora coautores no processo. Um encaixe complexo, outra vez, considerando esta autoria múltipla, envolvendo os participantes, o professor (o texto da semana era de minha autoria) e os autores usados. Nas atividades 'póschat', a coordenação mútua acabou por dividir, também, em caráter de trabalho cooperativo, as tarefas de construção do texto coletivo, em atividades de organização, revisão e postagem. A participação foi, neste particular, muito bem distribuida. 


\section{Resultados e considerações finais}

Cabe ressaltar um ponto interessante sobre a motivação dos participantes em relação à disciplina. A participação se revelava intensa, com mais de vinte horas de dedicação já cumpridas, contando as semanas anteriores. Quando do chat relâmpago, vale transcrever alguns comentários dos alunos do grupo B sobre a experiência:

\begin{tabular}{|l|l|}
\hline Aluno 5 & $\begin{array}{l}\text { Acredito que montamos um referencial teórico interessante, que abarca } \\
\text { a teoria que nos foi apresentada. É muito bom aprender com um } \\
\text { grupo como este! }\end{array}$ \\
\hline Aluno 6 & Terminou nosso tempo! \\
\hline Aluno 6 & Acho que foi muito legal. \\
\hline Aluno 7 & Demais! \\
\hline Aluno 7 & Agitado. \\
\hline Aluno 7 & Enriquecedor. \\
\hline Aluno 8 & Muito bom! (...) \\
\hline Aluno 9 & Como dizem meus alunos, foi "tenso!". \\
\hline
\end{tabular}

Sem a motivação em alta, seria muito improvável o êxito na utilização da avaliação multidimensional. As atividades têm de ser, como a avaliação, múltiplas, de forma a cobrir um amplo campo de teorias, experiências, cogitações pessoais, trajetórias, características individuais, etc. Como consequência, a carga de trabalho é maior, pedindo mais dedicação dos alunos. Com um planejamento pormenorizado e flexivel, de forma a adaptar-se sem perda de qualidade às demandas das pessoas envolvidas, valorizando os saberes individuais e a sinergia do grupo, é possível aliar a motivação mencionada a um processo significativo de construção colaborativa do conhecimento. Além disso, este é um modo de entender e trabalhar com a complexidade sem deixar-se perder, já que a mesma está presente na construção do conhecimento pertinente, não podendo ser ignorada. As atividades que dão conta deste aspecto complexo da aprendizagem aliam experiências pessoais dos profissionais já em exercício na profissão de DI (no caso), mais as reflexões de caráter teórico, além dos elementos novos surgidos no âmbito dos debates e das trajetórias colaborativas. Neste caldo, denso, o âmbito da avaliação multidimensional: todas as atividades, todas as intervenções, todos os aspectos.

Outro ponto de destaque é a possibilidade aberta ao acompanhamento das trajetórias individuais de aprendizagem, fator preponderante para a avaliação multidimensional em suas bases processuais, de acordo com Kenski, Oliveira e Clementino (2006). Isto também aconteceu quando da ocorrência do chat relâmpago, usado na terceira semana do curso. Do ponto de vista da avaliação multidimensional, foi possivel perceber as participações efetivas de cada um dos envolvidos, além da relevância das mesmas. 
Especificamente quanto ao chat relâmpago, tomando por base o texto da semana três, por exemplo, pode-se observar que Aluno 2 e Aluno 3 estavam, na maior parte do tempo, mais presos à estrutura e conteúdo do mesmo, enquanto que Aluno 1, sem fugir às concepções ali expostas, agregou reflexões das outras semanas do curso, bem como seus posicionamentos construídos da experiência nas outras disciplinas do curso e em sua vida profissional. A participação de Aluno 4 nesta atividade, bastante discreta, ainda que com colocações pertinentes, é um caso à parte. 0 próximo quadro mostra a diferença entre o número de intervenções deste aluno e os demais. Ocorre, porém, que na continuidade do trabalho, feito em cooperação entre os componentes do grupo, envolvendo a publicação do chat, a confecção do texto, as revisões necessárias, a participação de Aluno 4 foi, também, bastante reduzida. Neste particular, outros componentes do grupo indicaram, por e-mail, que consideravam sua atuação suficiente, dando as razões pelas quais pensavam assim.

Em uma eventual quantificação, transformada em nota, a análise do produto chat relâmpago talvez levasse este participante à reprovação. Não foi o caso. 0 fato de 0 Aluno 4 ter feito menos não significa que não tenha feito com qualidade. A análise do processo de construção encetado na atividade - inclusive com as conexões existentes em outros espaços, como o fórum e o e-mail - permitiram a percepção de que Aluno 4 de fato colaborara, de forma efetiva. Claro que a participação dos outros colegas não só foi maior como mais significativa. Ora, em uma atividade em que a estratégia é a de dar voz a todos, seria de se esperar, em uma primeira análise, que todos participassem igualmente. Este simplismo, entretanto, não cabe no âmbito da avaliação multidimensional, enquanto forma de superação da lógica do exame.

Ainda quanto ao caso do Aluno 4, os estilos de comunicação são diferentes de pessoa para pessoa: uns se dão melhor no meio síncrono, outros, no assíncrono; a intervenção de alguns é mais sintética, de outros, mais ampla; as condições pessoais, e isto aconteceu em grande medida neste caso, são facilitadoras ou complicadoras, o que deve ser levado em conta. É preciso não esquecer que a multidimensionalidade comunicacional é uma condição dos AVA estabelecidos no ciberespaço, nos quais a consciência do outro, como afirma Peraya (2002) e a possibilidade de intervenção nas mensagens, vistas como manipuláveis em um contexto não linear (Silva, 2003), também são dimensões de intervenção. Em seus trabalhos na disciplina, principalmente na elaboração do texto individual, que reflete significativamente as construções coletivas, Aluno 4 demonstra que sua participação no âmbito dos debates foi expressiva, apesar de mais silenciosa que a da maioria.

Da mesma forma, é preciso lembrar, também, o caráter interdisciplinar da estratégia empregada na atividade, para entender que as lógicas trabalhadas nas outras disciplinas sustentavam discussões de caráter amplo, que se estenderam em outros chats e em mensagens via e-mail, o que, no caso de Aluno 4 (e dos outros, igualmente) permitia um acompanhamento em outras frentes. 
Outro ponto de destaque é o tempo, ou melhor, a maneira como se apresenta a noção de tempo cronológico na consecução da atividade. Esta forma de observação do tempo aparece, na forma de controle, na transcrição do chat do Grupo B. Um membro do grupo seguia administrando o tempo, bem como o revezamento entre aqueles que detinham a palavra. 0 mesmo aconteceu no Grupo A, cujos membros observaram o fechamento da tarefa em 28 minutos. Entretanto, assim que o chat termina, assume (ou retorna) a lógica da intemporalidade, presente na divisão de tarefas para a criação do texto coletivo, na indicação de interações simultâneas que ocorreriam em diversas interfaces para o fechamento do trabalho.

Além disso, mesmo enquanto perdura o controle no chat, não se trata do tempo acrisolado no espaço de lugares, mas de outro, ele mesmo ainda sobre a influência da intemporalidade: os participantes manifestam surpresa ao observarem a riqueza da produção em tempo considerado tão reduzido, e alegam que, em outras ambiências, o trabalho renderia bem menos. É a velocidade oportunizada pelas articulações das tecnologias digitais em rede, mencionada por Delors e outros (1998), presente naquilo que Lévy $(1993$, p. 127) chama de terceiro tempo do espírito, o polo informático-mediático, no qual a dinâmica sugere "velocidade pura, sem horizonte", no qual a coincidência histórica entre tempo e espaço é superada pelas pessoas em todos os lugares, em tarefas múltiplas, de acordo com Kenski (2003).

Assim, em todos os tempos e em espaços de fluxos, a avaliação multidimensional encontrava seu campo de atuação. A amplitude destas conexões espaçotemporais permitia aos alunos realizar as construções associadas ao progresso na disciplina; em contrapartida, a mim se reservavam as possibilidades de acompanhar quando as interações ocorriam ou depois, recuperando os registros das trocas efetuadas. Memória, a qual, no ciberespaço, segundo Lévy (1993, p. 127), "encontra-se quase que totalmente objetivada em dispositivos técnicos". Ou seja, a ordenação dos acontecimentos significativos - recuperação de uma fala que subsidie o acompanhamento individual, leitura de um trabalho postado no portfólio, acompanhamento de discussão no fórum, junto de eventual intervenção - permanecem, como assevera Castells (2002, p. 487), distantes do ritmo cronológico, mas organizadas em "sequências temporais condicionadas ao contexto social de sua utilização".

Os elementos descritos neste artigo estão entre aqueles que tornam possivel a multidimensionalidade na avaliação da aprendizagem em cursos on-line. Os momentos e formas de avaliar não são separados em antes, durante e depois da passagem do aluno por um curso, mas todas as abordagens se aplicam em um mesmo movimento. Com suporte nas tecnologias, sim, mas com foco intensamente colocado nas pessoas, participantes do processo, professores e alunos. 
Em função das pessoas, então, em primeira e última análise, o processo de avaliação multidimensional deve ser pensado, de forma a valorizar o que cada um sabe, as formas como sabe e as maneiras como este saber pode ser empregado em benefício de todos os envolvidos em uma iniciativa de ensino-aprendizagem. Usuárias das interfaces, dos ambientes, do ciberespaço, da vida, que as pessoas possam estar sempre no centro dos projetos e das estratégias, das intenções e das abordagens. E da avaliação. Multidimensionalmente.

\section{Referências}

ALMEIDA, M. E. B. Educação a distância na internet: abordagens e contribuições dos ambientes digitais de aprendizagem. Educação e Pesquisa, São Paulo, v. 29, n. 2, p. 327-340, jul./dez. 2003.

BRASIL. Decreto $n^{\circ}$. 2.494, de 10 de fevereiro de 1998. Regulamenta o art. 80 da Lei no 9.394, de 20 de dezembro de 1996, e dá outras providências. TV Escola, Brasilia, DF, 10 fev. 1998. Disponivel em: <http://portal.mec.gov.br/seed/arquivos/ pdf/tvescola/leis/D2494.pdf>. Acesso em: 30 mar. 2010.

. Ministério da Educação. Portaria no. 3.712, de 11 de dezembro de 2003. Diário Oficial da União, Brasilia, DF, 12 dez. 2003. Seção 1, p. 10.

. Ministério da Educação. Relatório para a UNESCO da Comissão Internacional sobre Educação para o século XXI. Brasília, DF, 1998.

BRUNO, A. R.; MORAES, M. C. 0 enfoque da complexidade e dos aspectos emocionais na avaliação da aprendizagem online. In: SILVA, M.; SANTOS, E. (Org.). Avaliação da aprendizagem em educação on-line. São Paulo: Loyola, 2006.

CASTELLS, M. A sociedade em rede: a era da informação: economia, sociedade e cultura. São Paulo: Paz e Terra, 2002.

DELORS, J. et al. Educação, um tesouro a descobrir. In: BRASIL. Ministério da Educação. Relatório para a Unesco da Comissão Internacional sobre educação para o Século XXI. Brasília, 1998.

FAZENDA, I. C. A. Interdisciplinaridade: história, teoria e pesquisa. 12. ed. Campinas, SP: Papirus, 2005.

FRIGOTTO, G. Interdisciplinaridade como necessidade e como problema nas ciências sociais. In: JANTSCH, A. P.; BIANCHETTI, L. (Org.). Interdisciplinaridade: para além da filosofia do sujeito. Petrópolis: Vozes, 1995. 
GAMA, Z. J.; OLIVEIRA, H. A avaliação da aprendizagem: a proposta do curso de Pedagogia a distância do Consórcio CEDERJ. In: In: SILVA, M.; SANTOS, E. (Org.). Avaliação da aprendizagem em educação on-line. São Paulo: Loyola, 2006.

HARASIM, L. et al. Redes de aprendizagem: um guia para ensino e aprendizagem on-line. São Paulo: Senac, 2005.

HOFFMANN, J. Avaliação: mito e desafio: uma perspectiva construtivista. Porto Alegre: Mediação, 2005.

JACOBS, R. L. Human performance technology: a systems-based field for the training and development profession: Columbus: ERIC Publication, 1987. (Information series; n. 326).

KENSKI, V. M. Tecnologias e ensino presencial e a distância. Campinas, SP: Papirus, 2003.

KENSKI, V. M.; OLIVEIRA, G. P.; CLEMENTINO, A. Avaliação em movimento: estratégias formativas em cursos online. In: SILVA, M.; SANTOS, E. (Org.). Avaliação da aprendizagem em educação on-line. São Paulo: Loyola, 2006.

KURZ, R. A ignorância da sociedade do conhecimento. Folha de S. Paulo, São Paulo, 13 jan. 2002. Mais!, p. 1-4.

LÉVY, P. Tecnologias da inteligência. São Paulo: Ed. 34, 1993.

LUCKESI, C. C. Avaliação da aprendizagem escolar: estudos e proposições. São Paulo: Cortez, 2001.

MINAYO, M. C. S. O desafio do conhecimento: pesquisa qualitativa em saúde. 3. ed. São Paulo: Hucitec; Rio de Janeiro: Abrasco, 1994.

MORIN, E. A cabeça bem-feita. 3. ed. Rio de Janeiro: Bertrand Brasil, 2001a. . Ciência com consciência. 5. ed. Rio de Janeiro: Bertrand Brasil, 2001 b.

. Os sete saberes necessários à educação do futuro. 5.ed. São Paulo: Cortez; Brasilia, DF: UNESCO, 2002.

OLIVEIRA, G. P. Avaliação em cursos on-line colaborativos: uma abordagem multidimensional. 2007. 200 f. Tese (Doutorado) - Faculdade de Educação, Universidade de São Paulo, São Paulo, 2007. 
OTSUKA, J. L. et al. Suporte à avaliação formativa no ambiente de educação à distância TelEduc. In: CONGRESSO IBEROAMERICANO DE INFORMÁTICA EDUCATIVA, 6., 2002, Vigo. Anais... Vigo, ES, 2002. Disponível em: <http:// www.teleduc.org.br/artigos/18_jrth_ie2002.pdf>. Acesso em: 23 fev.2010.

PALOFF, R. M.; PRAT, K. O aluno virtual: um guia para trabalhar com estudantes on-line. Porto Alegre: Artmed, 2004.

PALOFF, R. M.; PRAT, K. Construindo comunidades de aprendizagem no ciberespaço: estratégias eficientes para salas de aula on-line. Porto Alegre: Artmed, 2002.

PERAYA, D. 0 ciberespaço: um dispositivo de comunicação e de formação midiatizada. In: ALAVA, S. (Org.). Ciberespaço e formações abertas: rumo a novas práticas educacionais. Porto Alegre: Artmed, 2002.

POMBO, 0. Interdisciplinaridade e integração dos saberes. In: CONGRESSO LUSO-BRASILEIRO SOBRE EPISTEMOLOGIA E INTERDISCIPLINARIDADE NA POSGRADUAÇÃO, 2004, Porto Alegre. Conferência apresentada... Porto Alegre: PUCRS, 2004. Transcrição. Disponível em: <http://www.educ.fc.ul.pt/docentes/ opombo/investigacao/porto\%20alegre.pdf>. Acesso em: maio 2009.

PRIMO, A. Avaliação em processos de educação problematizadora on-line. In: SILVA, M.; SANTOS, E. (Org.). Avaliação da aprendizagem em educação on-line. São Paulo: Loyola, 2006.

ROTHWELL, W. Beyond training and development: state-of-the-art strategies for enhancing human performance. New York: AMACOM, 1996.

SANTOS, E. Portfólio e cartografia cognitiva: dispositivos e interfaces para a prática da avaliação formativa em educação on-line. In: SILVA, M.; SANTOS, E. (Org.). Avaliação da aprendizagem em educação on-line. São Paulo: Loyola, 2006.

SEIZER, V. Dado, informação, conhecimento e competência. São Paulo: USP, 1999. Disponível em: <http://www.ime.usp.br/ vwsetzer/datagrama.html>. Acesso em: maio 2009.

SILVA, M. Criar e professorar um curso on-line: relato de experiência. In: SILVA, M. (Org.). Educação on-line. São Paulo: Loyola, 2003.

SILVA, M. O fundamento comunicacional da avaliação da aprendizagem na sala de aula on-line. In: SILVA, M.; SANTOS, E. Avaliação da aprendizagem em educação on-line. São Paulo: Loyola, 2006. 
TORRES, P. L.; BOCHNIAK, R. Avaliação em educação a distância numa perspectiva interdisciplinar. In: SILVA, M.; SANTOS, E. (Org.). Avaliação da aprendizagem em educação on-line. São Paulo: Loyola, 2006.

VIGOTSKY, L. S. A formação social da mente. 6. ed. São Paulo: Martins Fontes, 1998.

WILLIS, J. The maturing of constructivist instructional design: some basic principles that can guide practice. Educational Technology, Washington, DC, v. 40, n.1, p. 5-16, 2000.

Recebido em: 02/09/2008

Aceito em: 13/01/2010 